\title{
Effect of the Ethanolic Extract of Scoparia dulcis in Cisplatin induced Nephrotoxicity in wistar rats
}

\author{
Smitha Jose ${ }^{1 *}$ and Sreedevi Adikay ${ }^{2}$ \\ 1'Department of Pharmaceutical Chemistry, Visveswarapura Institute of Pharmaceutical Sciences, Benashankiri, Bangalore 560080 , \\ Karnataka, India. (affiliated to R.G.U.HS) \\ ${ }^{2}$ Department of Pharmaceutical Technology, Sri Padmavathy Mahila Visvavidyalayam University, Thirupati 517 502, Andra Pradesh, \\ India. (affiliated to S.P.M.V.U.)
}

\begin{abstract}
Objective: To evaluate the nephroprotective potential of ethanolic extract of aerial parts of plant Scoparia dulcis against cisplatin induced nephrotoxicity in Wistar rats. Materials and Methods: Nephrotoxicity was induced by a single intra-peritoneal administration of Cisplatin $(6 \mathrm{mg} / \mathrm{kg})$ in wistar rats. Nephroprotective potential of plant was tested at two different doses in curative regimen and for a single dose of $400 \mathrm{mg} / \mathrm{kg}$ in prophylactic control. Nephrotoxicity was characterised by induced marked renal failure, significant increase in blood urea nitrogen, serum creatinine level, lipid peroxidation levels and significant decrease in urinary creatinine clearance. Histopathological studies confirmed tubular necrosis. Supplementation of ethanolic extract of Scoparia dulcis reduced the elevated serum creatinine, blood urea nitrogen levels, lipid peroxidation levels and improved the creatinine clearance. Results and Discussion: Our experimental results suggest that supplementation of Scoparia dulcis during cisplatin therapy reduces the risk of cisplatin induced nephrotoxicity in a dose dependent manner in curative regimen. The prophylactic regimen also possessed significant nephroprotection against cisplatin toxicity. The protective effect of Scoparia dulsis in curative and prophylactic regimen may be due to the antioxidant property of Scoparia dulcis. These findings suggest the significant nephroprotection of Scoparia dulcis against cisplatin nephrotoxicity.
\end{abstract}

Key words: Nephrotoxicity, Scoparia dulcis, Cisplatin, lipid Peroxidation, anti-oxidant.

\section{INTRODUCTION}

Scoparia dulcis is a perennial herb, belongs to the family Scophulariaceae is distributed throughout the tropical and subtropical region of the world and is known as Vassourinha in India. ${ }^{1}$ Traditionally the fresh or dried plant has been used as a remedy for treating diseases such as; stomach ailments, hypertension, diabetes, inflammation bronchitis, haemorrhoids, analgesic, antipyretic and urinary disorders. Plant is also used for upper respiratory bacterial and viral infections, to relieve from all types of pain, to tone balance, strengthen heart function, for veneral diseases and urinary tract infections. ${ }^{2}$ The leaf of Scoparia dulcis is used for diabetes in India. Recently studies have been carried on the extract of aerial parts of Scoparia dulcis for potential uses including pain relieving antispasmodic, anti inflammatory activities. ${ }^{3}$
Plant is also reported to possess cytotoxic, anti cancerous, ${ }^{4}$ antimicrobial, anti malarial, ${ }^{5}$ anti ulcer, antacid, ${ }^{6}$ anti diabetic, anti cholestrol $^{7}$ and antioxidant actions. ${ }^{8}$

The cisplatin is a water soluble anticancer drug, organic complex formed by an atom of platinum surrounded by chloride and ammonium atoms. The mechanism of action include after entering the cell, the chlorine ions dissociates leaving a reactive complex. This complex reacts with water and then interacts with DNA resolving in denaturation of DNA chain. Cisplatin also damages cell mitochondria arrests cell cycle in $G_{2}$ phase inhibits ATPs activity, alters the cellular transport system and eventually causing apoptosis, ${ }^{9}$ inflammation, ${ }^{10}$ necrosis and death in cells. Although it is a potent
Submission Date : 03-02-2015 Revision Date : :02-04-2015 Accepted Date : :25-05-2015

DOI: $10.5530 /$ ijper.49.4s.8 Correspondence Address Mrs. Smitha Jose Assistant Professor Visveswarapura Institute of Pharmaceutical Sciences Benashankari, 2nd stage Bangalore 560080 Karnataka, India. E-mail:smitha708@gmail. com

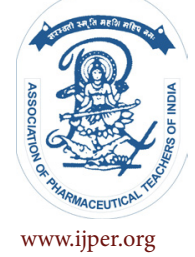



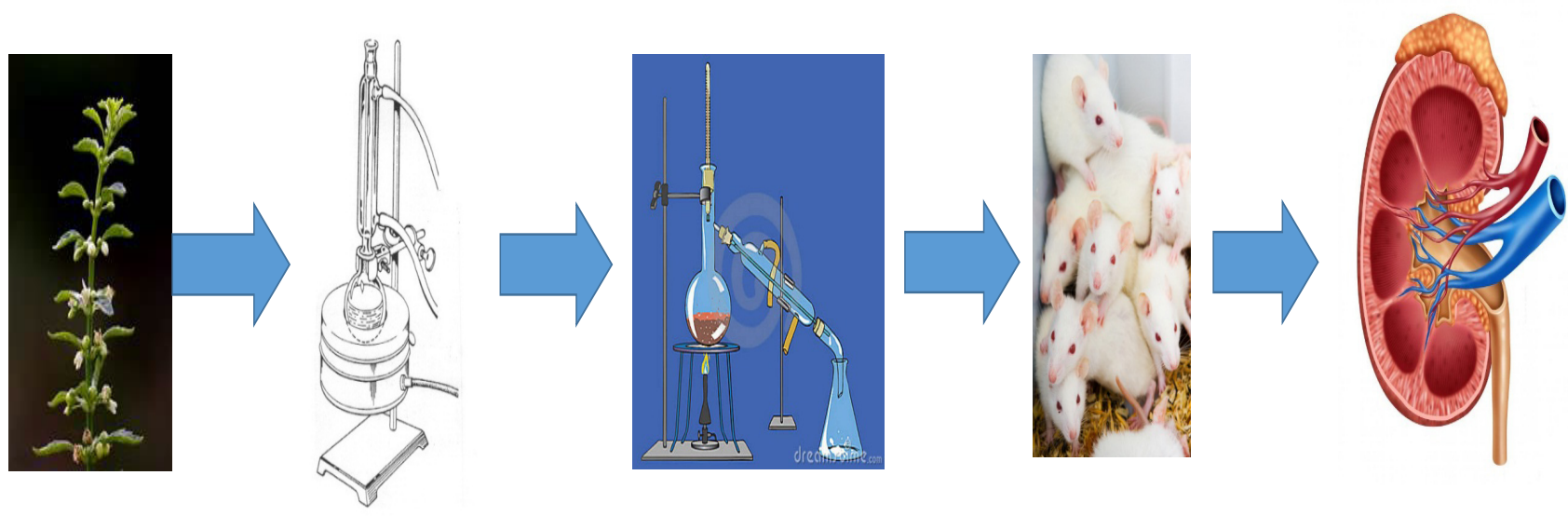

\section{Graphical Abstract}

anticancer, the major drawback associated with cisplatin is kidney damage. Previous reports showed evidences of cisplatin predominantly localized in the $\mathrm{S}_{3}$ segments of proximal tubules in the corticomedullary region. ${ }^{11}$

In allopathy till date there is no effective drug reported to treat the nephrotoxicity of cisplatin. The effectiveness of herbal extracts for the urinary diseases is as old as humankind itself. Eventhough Scoparia dulcis used as an ethnomedicine against urinary disorders, there is no pharmacological validation for its traditional use. Hence the present study was designed to establish the nephroprotective property of ariel parts of Scoparia dulcis. The ethanolic extract was used to evaluate the cisplatin induced nephrotoxicity and dysfunction in wistar rats.

\section{MATERIALS AND METHODS}

\section{Materials}

\section{Plant material collection and authentification}

The aerial parts of plant Scoparia dulcis was collected from Idukki, Kerala, India and authentified by the department of botany, Nagarjuna Ayurveda Centre, Alakode, Thodupuzha, India. A specimen voucher was deposited in college (Visveswarapura Institute of Pharmaceutical Sciences) herbarium for future references. The drug cisplastin was a gifted sample from Caplin Point Laboratories, Pondicherry, India. All other chemicals used were analytical grade.

\section{Preparation of extract}

The plant (1000 gm) was shade dried and coarsely powdered for extraction with alcohol at $60-70^{\circ} \mathrm{C}$ for 3 hour and the filtrate was concentrated under vaccum. The residue collected (20 gm) was thick, green in colour and gumaceous in nature and stored at below $20^{\circ} \mathrm{C}$. The required extract was dissolved in suitable vehicle and used for investigation.

\section{Pharmacological Studies}

\section{Acute toxicity studies}

Acute toxicity studies were performed on albino mice of either sex weighed (25-30 gm). The acute oral toxicity study ${ }^{12}$ was carried out as per guide lines set by organisation for economic corporation and development (OECD) received from committee for the purpose of control and supervision of experiments on animals. One tenth of median lethal dose $\left(\mathrm{LD}_{50}\right)$ was taken as effective dose. ${ }^{13}$

\section{Animal selection}

Wistar rats weighing between 200 and $250 \mathrm{~g}$ were selected for nephroprotector activity. The animals were acclimatised to standard laboratory conditions at $(25 \pm$ $0.2^{\circ} \mathrm{C}$ and maintained for 12 hour day and night cycle). They were provided with regular rat chow and drinking water. The animals care and experimental protocols were in accordance with Institutional Animal Ethical Committe (IAEC, Reg.No.152/1999/CPCSE).

\section{Experimental model for Nephroprotector activity}

Wistar rats were weighed (200-250 g) and divided into 6 groups of six animals each. Group-I, received (1\% tween 80) for 15 days and Group-II, (curative control) received cisplatin (6 mg/Kg, i.p; single dose) on the first day and vehicle $(1 \%$ tween 80$)$ from day 6 - day $15^{\text {th }}$. Group-III, received cisplatin on first day and plant extract $(200 \mathrm{mg} / \mathrm{Kg})$ from day6 to day $15^{\text {th }}$. GroupIV, treated with cisplatin on first day and plant extract (400 mg, higher dose) from day 6 to day $15^{\text {th }}$. Group-V, acts as a prophylactic control in which the animals are given with vehicle from day 1 to day $10^{\text {th }}$ and cisplatin on $11^{\text {th }}$ day. Group-VI, is treated with plant extract ( $S_{c o-}$ paria dulcis) from day 1 to day $10^{\text {th }}$ and cisplatin on $11^{\text {th }}$ day. On $16^{\text {th }}$ day blood and urine are collected from all six groups for biochemical estimation. The estimation 


\begin{tabular}{|c|c|c|c|}
\hline Groups $n=6$ & $\begin{array}{l}\text { BUN (mg/ } \\
\text { dl) }\end{array}$ & $\begin{array}{c}\text { Serum } \\
\text { creatinine (mg/ } \\
\text { dl) }\end{array}$ & $\begin{array}{c}\text { Lipid } \\
\text { Peroxidation } \\
\text { (percentage } \\
\text { inhibition) }\end{array}$ \\
\hline Groupl & $25.3 \pm 1.4$ & $0.5 \pm 0.6$ & - \\
\hline Groupll & $49.4 \pm 1.6$ & $2.7 \pm 0.7$ & - \\
\hline GroupIII & $35.4 \pm 0 .{ }^{* a}$ & $2.0 \pm 0.5^{\star a}$ & $18^{* a}$ \\
\hline GroupIV & $26.7 \pm 1.3^{* t b}$ & $0.9 \pm 0.4^{* * b}$ & $40^{* * b}$ \\
\hline GroupV & $51.9 \pm 1.7$ & $2.3 \pm 0.5$ & - \\
\hline GroupVI & $30.8 \pm 0.9^{* * c} \mathrm{c}$ & $1.1 \pm 0.8^{* * c}$ & $19^{* \mathrm{c}}$ \\
\hline
\end{tabular}

Mean $\pm S D, n=6$, *significant pharmacological activity, **Potent pharmacologicalactivity.

${ }^{*} \mathrm{P}<0.05$ compared with curative control ; ${ }^{* * \mathrm{~b}} \mathrm{P}<0.01$. compared with curative control $;{ }^{* *} \mathrm{P}<0.01$. compared with prophylatic control.

of biochemical parameters include Blood urea nitrogen (BUN, Diacetyl monooxime method), serum creatinine (Alkaline picrate method), Serum total proteins (Biuret method), Urinary protein (Sulphosalicilic acid method) using UV-Visible spectrophotometer by following standard methods. For histopathological studies and lipidperoxidation studies in kidney, the rats from each group have to be anaesthetised using sodium phenobarbitone $(60 \mathrm{mg} / \mathrm{Kg})$ and kidneys were isolated.

\section{Serum Analysis}

The blood was collected from the retro-orbital on $15^{\text {th }}$ day from animals and they were anasthetized using sodium phenobarbitone $(60 \mathrm{mg} / \mathrm{Kg})$. The serum was separated by centrifugation at $10000 \mathrm{rpm}$ for $10 \mathrm{~min}$ and analysed for biochemical parameters such as serum creatinine, (Alkaline picrate method), blood urea nitrogen (Diacetyl monooxime method) ${ }^{14}$ and uric acid. ${ }^{15}$

\section{Urine Analysis}

All animals were kept in individual metabolic cages and urine samples were collected. The animals had free access to drinking water during the urine collection period. The urine was collected to analyse creatinine clearance and urinary protein. (Sulphosalicilic acid method). ${ }^{16}$

\section{In vivo lipid peroxidation in cisplatin induced nephrotoxicity}

The degree of lipid peroxide formation was assayed by monitoring thiobarbituric reactive substance formation. Stock solution of $15 \% \mathrm{w} / \mathrm{v}$ trichloroacetic acid (TCA), $0.375 \% \mathrm{w} / \mathrm{v}$ of thiobarbituric acid (TBA) and 0.25 $\mathrm{N}$ Hydrochloride acid ( $\mathrm{HCl})$. The solution was mildly heated to assist the dissolution of TCA. Further combine $1 \mathrm{~mL}$ of biological sample (1-2 $\mathrm{mg}$ of memberane protein or 0.1-0.2 $\mu$ mole of lipid phosphate) with 2 mL of TCA-TBA HCL and mixed thoroughly. Then the solution was heated for one hour in a boiling water bath and allowed to cool. After cooling, the flocculent precipitate was removed by centrifugation at $2500 \mathrm{rpm}$ for $2 \mathrm{~min}$ and at $535 \mathrm{~nm}$ against the blank. The concentration of malondialdehyde of the sample was calculated by following formula using an extinction coefficient $1.56 \times 10^{5} \mathrm{M}^{-1} \mathrm{~cm}^{-10} \%$ inhibition.

$$
\text { Inhibition }(\%)=\frac{\text { Control OD }- \text { Test OD }}{\text { Control OD }}
$$

\section{Histopathological studies}

The extraneous tissues of isolated kidneys were cleaned off and preserved in neutral formalin $(10 \%)$ solution. Formalin preserved samples of kidneys from various groups were studied for histopathological changes during experimental section of kidneys stained with haematoxylin and eosin were observed under standard microscope. The centrifuged homogenate was used for lipid peroxidation studies.

\section{Stastical Analysis}

All data are subjected to one way ANOVA followed by Dunnetts test. The $\mathrm{P}$ value of $<0.05$ was considered stastically significant. The stastical analysis was performed using Prism Software for windows.

\begin{tabular}{|c|c|c|c|}
\hline \multicolumn{4}{|c|}{ Table 2: Effect of ethanolic extract on urine parameters } \\
\hline Groups & $\begin{array}{c}\text { Creatinine clearance } \\
\text { (ml/h/100 g Bd.Wt) }\end{array}$ & $\begin{array}{c}\text { Urine totalprotein } \\
\text { (mg/day) }\end{array}$ & $\begin{array}{c}\text { Urine volume } \\
\text { (ml/day) }\end{array}$ \\
\hline I & $17.8 \pm 1.3$ & $5.7 \pm 0.8$ & $12.13 \pm 0.7$ \\
\hline II & $8.4 \pm 0.2$ & $16.8 \pm 2.5$ & $4.2 \pm 0.2$ \\
\hline III & $11.5 \pm 0.3^{* a}$ & $12.5 \pm 0.3^{* a}$ & $6.4 \pm 0.3^{* a}$ \\
\hline IV & $14.7 \pm 0.2^{* \mathrm{~b}}$ & $7.1 \pm 0.5^{* \mathrm{~b}}$ & $10.6 \pm 0.2^{\mathrm{b}}$ \\
\hline V & $7.2 \pm 0.2$ & $14.9 \pm 1.2$ & $5.9+0.2$ \\
\hline VI & $12.8 \pm 0.2^{* * \mathrm{c}}$ & $9.2 \pm 0.3^{* * \mathrm{c}}$ & $9.8 \pm 0.2^{* * \mathrm{c}}$ \\
\hline
\end{tabular}

Mean $\pm S D, n=6$, *Significant pharmacological activity, **Potent pharmacological activity. ${ }^{*} \mathrm{P}<0.05$, ** $\mathrm{P}<0.01 ;{ }^{*} \mathrm{P}<0.05$ compared with curative control; ${ }^{* * b} \mathrm{P}<0.01$.compared with curative control; ${ }^{* *} \mathrm{P}<0.01$.compared with prophylatic control. 


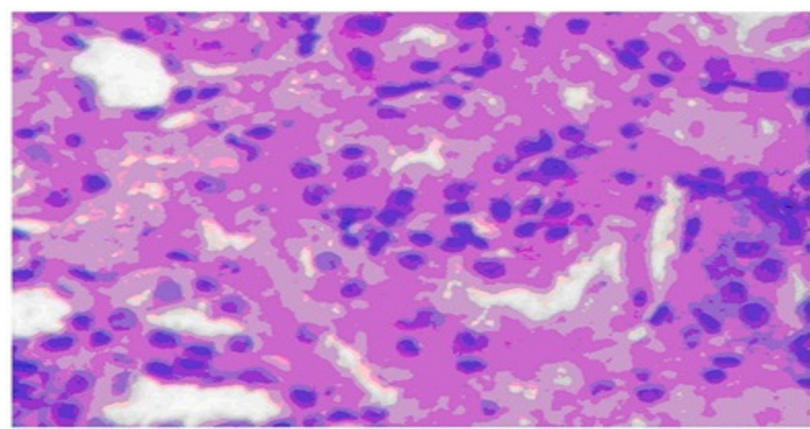

Figure 1: The normal control showed (Figure 1) the structure of kidney with nomal glomerulai, proximal and distal tubules and with normal interstitium and blood vessels

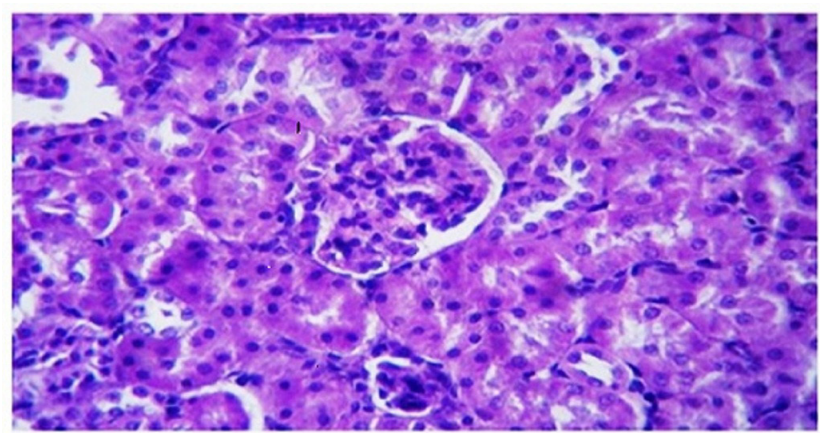

Figure 3: Curative regimen treatment done with $200 \mathrm{mg} / \mathrm{Kg}$ ethanolic extract showed (Figure 3) structure of the kidney with maintained glomerulai, proximal and distal tubules, there were less interstitial congestion and showed recovery of interstitial congestion

\section{RESULTS}

\section{Effect of Scoparia dulcis on serum parameters}

The effect of Scoparia dulcis on serum parameters is represented in Table 1. Animals which received only cisplatin induced nephrotoxicity characterised by increased levels of serum creatinine, and Blood Urea Nitrogen (BUN) when compared with the normal control. Upon supplementation of Scoparia dulcis to the cisplastin treated animals with (Grp III \& IV), showed a significant reduction in BUN and serum creatinine was observed. The group IV with higher dose of $400 \mathrm{mg} / \mathrm{kg}$ body weight of Scoparia dulcis reduced the values to the extent of $\mathrm{p}<0.01$ when compared to positive control. This shows a dose dependent effect of extract in curative regimen. In prophylactic regimen the treatment with extract (Grp VI, $400 \mathrm{mg} / \mathrm{kg}$ ) for ten days showed a significant reduction in serum marker levels in group VI when compared to normal control.

\section{Effect of Scoparia dulcis on urine parameters}

The effect of cisplatin and extract on the renal functions was represented in Table 2. The administration of cisplastin caused significant reduction $(\mathrm{P}<0.05)$ in creatinine clearance and increased the excretion of urinary

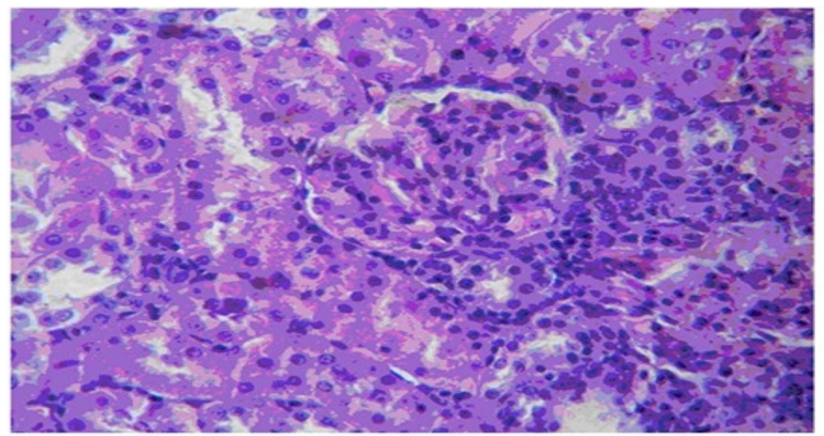

Figure 2: A positive control ie, cisplastin treated group showed (Figure 2) glomeruline unremarkable, most of the tubules showed desquamation along with epithelial casts and showed massive total necrosis

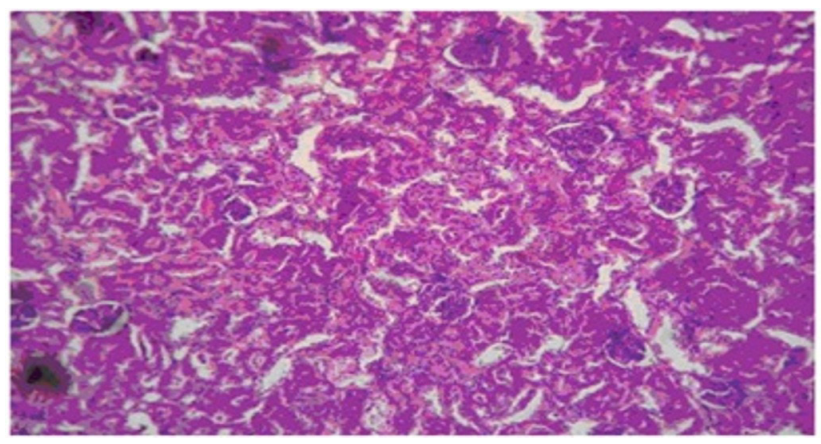

Figure 4: Curative regimen treatment done with $400 \mathrm{mg} / \mathrm{Kg}$ ethanolic extract showed (Figure 4), structure of kidney with maintained glomerulai, proximal and distal tubules, there was no congestion and indicated interstitial congestion like normal

protein in curative control and preventive control when compared to the normal control groups. In curative regimen, animals which were treated with extracts in ( Groups III and IV), increased creatinine clearance and reduced the elevated levels of total protein excretion. Animals of the preventive regimen (Group-VI) showed significant protection against cisplastin induced effects.

\section{Lipid Peroxidation}

Administration of cisplastin caused significant increase in the levels of Malon Dialdehyde (MDA) in curative control (Group-II) and preventive control (Group-V) when compared to normal control group $(\mathrm{p}<0.05)$. This indicated that increased lipid peroxidation in Group-II and $V$ animals. A significant reduction in MDA level was observed in animals treated with plant extracts (Groups -III animals $(200 \mathrm{mg} / \mathrm{Kg})$ and Group - IV animals (400 $\mathrm{mg} / \mathrm{Kg}$ ) compared to curative control group. Animals treated with extract for ten days prior to the cisplatin administration decreased MDA levels.

\section{Histopathological Studies}

The above findings were supported by histopathological studies. Group II showed marked renal toxicity , characterized by congestion of glomeruli, presence of inflam- 


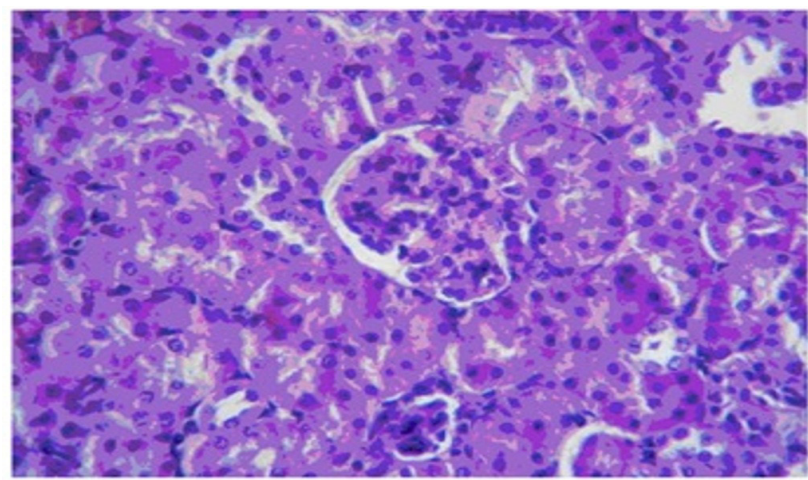

Figure 5: Prophylactic control showed (Figure 5), glomerulai unremarkable, tubules desquamation is seen along with epithelial casts, interstitium mild lymphocytic infiltration, and vessels unremarkable and showed residual interstitial nephritis

matory cells, desquamation of tubular epithelial cells etc. Both prophylactic and curative regimen showed good protection against cisplatin induced nephrotoxicity compared to control groups. (Figure 1-6)

\section{DISCUSSION}

The alcoholic extract of Scoparia dulcis was evaluated at two curative doses $(200 \mathrm{mg} / \mathrm{kg}$ and $400 \mathrm{mg} / \mathrm{kg}$ ) and one prophylactic dose $(400 \mathrm{mg} / \mathrm{kg})$. Our experimental results suggested that supplementation of Scoparia dulcis during cisplatin therapy reduces the risk of cisplatin induced nephrotoxicity in a dose dependent manner. The curative regimen showed significant amount of activity to prevent the effects of cisplatin, especially the higher dose of $400 \mathrm{mg} / \mathrm{kg}$ possessed significant protection of $\mathrm{p}<0.01$. The extract also showed significant preventive effect due to presence of sufficient amount of extract in animals to prevent the effects of cisplatin. Histopathological studies and lipid peroxidation studies support these findings.

Kidney is a complex and dynamic organ. Although excretion of wastes is the primary function, it also plays a significant role in regulation of total homeostasis. Regulation of extracellular volume and control of electrolyte and acid base balance are also important functions of kidney. A toxicological insult to the kidney could affect any one or all of these functions. The toxic effects of affected kidney will be reflected as decreased elimination of wastes, an increase in blood urea nitrogen, and an increase in plasma creatinine. These parameters are clinical indices of nephrotoxicity. We are vulnerable to nephrotoxicity due to some drugs and chemicals. Cisplatin is an effective anticancer drug which induces nephrotoxicity and there is no known drug available which effectively treat the nephrotoxicity of cisplatin. Reports suggested a single dose of intraperitoneal administration of cisplatin

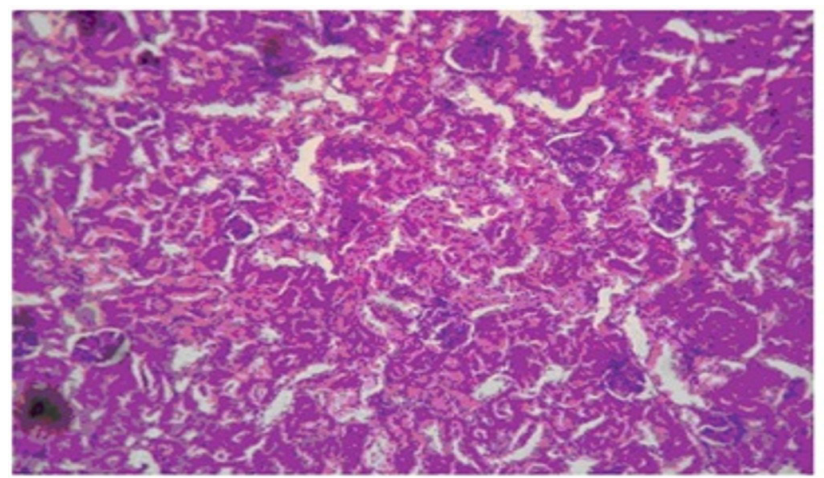

Figure 6: Prophylactic treatment done with $400 \mathrm{mg} / \mathrm{Kg}$ showed (Figure 6) structure of kidney with maintained glomerulai, proximal and distal tubules and showed less congestion

(6 mg/Kg) induced nephrotoxicity. ${ }^{17}$ Even though the mechanisms are clearly not known, several mechanisms have been suggested for cisplatin induced nephrotoxicity i.e., apoptosis, inflammatory mechanism and generation of reactive oxygen species. ${ }^{18}$ The nephrotoxicity due to cisplatin is a rapid process due to the reaction with the proteins in renal tubules. The renal damage is produced within one hour after administration. Hence the presence of protective agent in the renal tissues may reduce the toxic effects of cisplatin. This is the rationale behind the prophylactic treatment of plant extract.

Previous evidences have shown that cisplatin induced nephrotoxicity is by initiation of lipid per oxidation. ${ }^{19}$ There were also reports suggesting cisplatin exerts its nephrotoxicity by generation of free radicals. ${ }^{20}$ The general toxicity mechanism involves oxidative stress by the generation of reactive oxygen species such as hydrogen peroxide, superoxide anion, and hydroxyl radicals which are generated under normal cellular conditions and they are immediately detoxified by endogenous antioxidant enzymes superoxide dismutase (SOD), Catalase (CAT), and non enzymatic compounds as reduced glutathione (GSH). But the cisplatin accumulation in kidneys causes an imbalance in antioxidants due to loss of copper and zinc resulting in depletion of SOD and peroxidation of lipids. ${ }^{21}$ Hence the antioxidants and free radical scavengers of natural or semi synthetic and synthetic origin provide nephroprotection.

Earlier reports proved that plants possessing antioxidant principles such as pongamia pinnata, ${ }^{22}$ crataeva nurv$\mathrm{ala}^{23}$ exhibited nephroprotector activity against cisplatin induced renal damage. Tannins and flavanoids are well known for their antioxidant properties and free radical scavenging abilities. ${ }^{24} \mathrm{~A}$ relationship between oxidative stress and renal toxicity has been documented in several animal experimental models. ${ }^{25}$ Scoparia dulcis is one such plant rich in antioxidant constituents and was used 
by tribals of Kerala for kidney diseases. ${ }^{26}$ The leaves of Scoparia dulcis were reported to contain flavanoids scutellarien, and 7-o-methyl scutellarien. A flavone cirsitakaoside was also extracted from Scoparia dulcis. ${ }^{27}$ The nephroprotective effect of Scoparia dulcis may be due to the presence of well known antioxidants that can scavenge free radicals.

The measurement of lipid peroxidation is an efficient method of monitoring oxidative damage in tissues, which is determined by measurement of thiobarbituric acid substance. The concentration of lipid per oxidation products reflects the degree of oxidative stess and the malondialdehyde concentration (MDA) concentration is a measure of lipid peroxidation. Reactive oxygen species causes peroxidation of membrane lipids with devastating effects on functional and structural states. The preservation and restorage of cellular membrane integrity depends on protective and repair mechanism against renal tissue oxidative damage. Our data showed that cisplatin induced lipid peroxidation and was significantly reduced by the administration of plant extract in both curative and preventive regimen. The percentage of inhibition of lipid peroxidation was very significant in higher dose of curative regimen and also in the preventive ie, prophylatic regimen. These results indicates that the extract is involved in the protection of normal cell structure and function of homeostatsis.

As cisplatin is believed to induce oxidative stress which leads to a chain of complex biochemical reactions resulting in cellular damage by free radicals, here our data showed that the administration of Scoparia dulcis extract protects and also repairs the structure and functional changes due to their antioxidant potential.

\section{CONCLUSION}

Since our present study reveals the potential of Scoparia dulcis as a nephroprotective agent, it is suggested for further validation, quantitative and qualitative studies which may help in designing a novel drug in the area of nephrotoxicity and related problems.

\section{ACKNOWLEDGEMENTS}

Authors are grateful to VIPS, Bangalore for providing laboratory facilities during the course of experiment.

\section{SUMMARY}

- Cisplatin induces nephrotoxicity in wistar rats.

- Nephrotoxicity was characterized by marked renal failure, increased serum parameters and lipid peroxidation levels.

- Supplementation of scoparia dulcis during cisplatin therapy reduces nephrotoxicity in a dose-dependent manner.

- Scoparia dulcis also exhibited significant protection against cisplatin nephrotoxicity and can be used as prophylactic for nephrotoxicity.

\section{About Authors}

Smitha jose Presently working as Assistant Professor in Department of Pharmaceutical chemistry in Visveswarapura Institute of pharmaceutical Sciences in Bangalore and has one paper publication and one abstract.
Dr. Sreedevi Adikay Working as professor in Department of Pharmaceutical Technology, Sri Padmavathy Mahila Viisvavidyalayam University, Tirupati, Andra Pradesh. 517502. Dr. Sreedevi has 22 paper publications, also received in AICTCE-CAYT Award in 2007 and also has DST-WOS (A) UGC research award in 2014.

\section{REFERENCES}

1. Riel MA, Kyle DE, Milhous WK. Efficacy of Scopadulcic acid A against Plasmodium falciparum in vitro. J Nat. Prrod. 2002; 65(4): 614-5.

2. Latha M, Pari L, Sitasawad S, Bhonde R. Insulin -secretagogue activity and cytoprotective role of the traditional antidiabetic plant Scoparia dulcis. Life Sci. 2004; 75(16): 2003-14.

3. Ahmed B, Alam T, Khan SA. Hepatoprotective activity of Luffa echinata fruits. J Ethnopharmacol. 2001; 76(2): 187-9.

4. Kessler JH, Mullauer FB, De Roo GM, Medema JP. Broad in vitro efficacy of plant-derived betulinic acid against cell lines derived from the most prevalent human cancer types. Cancer Lett 2007; 18.251(1): 132-45.

5. Hayashi K, Niwayama S, Hayashi T, Nago R, Ochiai H, Morita N. In vitro and in vivo antiviral activity of scopadulcic acid B from Scoparia dulcis,
Scrophulariaceae, against Herpes simplex virus type 1. Antiviral Res. 1988; 9(6): 345-54.

6. Hayashi T, Kawasaki M, Miwa Y, Taga T, Morita N. Antiviral agents of plant origin III: Scopadulin, a novel tetracyclic diterpene from Scoparia dulcis L. Chem Pharm Bull. 1990; 38(4): 945-7.

7. Pari L, Latha M. Antihyperlipidemic effect of Scoparia dulcis (sweet broom weed) in streptozotocin diabetic rats. J Med Food. 2006; 9(1): 102-7.

8. Pari L, Latha M, Rao CA. Effect of Scoparia dulcis extract on insulin receptors in streptozotocin induced diabetic rats: studies on insulin binding to erythrocytes. J Basic Clin Physiol Pharmacol. 2004; 15(3-4): 223-40.

9. Hanigan M, Devaragan P. Cisplastin nephrotoxicity; molecular mechanisms. Can Ther. 2003; 1(1): 47-61. 
10. Ramesh G, Reeves WB. Inflammatory cytokines in acute renal failure. Kidney Int. 2004; 66(Suppl 91): 56-61.

11. Baddreldin HA, Mansour SA, Moundhri. Agents ameliorating or augmenting the nephrotoxicity of cisplastin and other platinum compounds. Food and Chemical toxicology 2004; 66(Suppl 91): 56-61.

12. Ghosh MN. Fundamentals of experimental Pharmacology Scientific Book Agency. Calcutta 1984; 33(5): 156-7.

13. Anupama Handa, Anupama SSH. Hepatoprotective activity of andrographolide from andro graphis paniculata against $\mathrm{CCl} 4$. Indian Journal of Medical Research 1990; 92(1): 276. [SD-008]

14. Godkar PB. Kidney function tests. In.: Text book of Medicinal Laboratory Technology. Bhalani publishing House, Bombay; 1994. 233-49.

15. Romero M, Perez M, Chuvez G, Parra Effect of uric acid on gentanycin induced nephrotoxicity in rats-role of matrix metalloprotinases 2 and 9 . Basic. Clin. Pharmacol. Toxicol. 2009; 105(1): 416-24.

16. Caraway WT, Uricacid D, Seligson. Editor, Standard Methods in Clinical Chemistry. Academic Press, Newyork, London; 1963. 4239

17. Sreedevi A, Barathi K, Prasad KVSRG. Effect of decotion of root bark of Berberis aristata against cisplatin induced nephrotoxicity in rats. Int. J. Pharm and Pharm Sci. 2009; 2(3): 51-6.

18. Dong Z, Atherton SS. Tumor necrosis factor in cisplatin nephrotoxicity: A home bred foe. Kid Int. 2007; 72(1): 5-7.

19. Ammar $\mathrm{AH}$, Sabah NA. Evaluation of the protective properties of amlodipine, on cisplatin induced cardiotoxicity in male rats. Glo $\mathrm{J}$ of Med res Interdsciplinary 2013; 13(2): 23-8.
20. Safirstein R, Miller P, Dikman S, Laymann N, Shapiro C. Cisplatin nephrotoxicity in rats. defect in papillary hypertonicity. Am. J. Physiol. Renal Physiol. 1981; 241(12): 175-85.

21. Ahamed MA, Sajida HI. Protective effect of ginger extract against cisplatin induced hepatotoxicity and cardiotoxicity in rats. Iraqi J Pharm Sci. 2012; 21(1): 27-33.

22. Annie Shirwaikar, Malini S, Chandrika Kumara S. Protective effect of Pongamia pinnata flowers against cisplatin and gentamycin induced nephrotoxicity in rats. Int. J of Exp. Bio. 2003; 41(1): 58-62.

23. Annie Shirwaikar, Manjunath Setty, Praveen Bommu. Effect of lupeol isolated from Crataeva nurvala Buch-Ham. stem bark against free radical induced nephrotoxicity in rats. Indian Journal of Experimental Biology 2004; 42(1): 686-90.

24. Yokozawa T, Suzuki N, Zhng PD, Oura H, Nishioka I. Effect of orally administered rhubab extract in rats wiyh chronic renal failure. Chem and Pharma. Bull. 1984; 32(11): 4506

25. Wegener T, Fintelmann V. Flavanoids and Bioactivity. Wein Med Wochem Schr. 1999; 149(6): 241-7

26. Adaikopoh MA, Orhue NEJ, Igbe I. The protective role of Scoparia dulcis on tissue antioxidant defense system of rats exposed to cadmium. African journal of biotechnology 2007; 16(10): 1192-6.

27. Monira Ahsaan SKN, Islam Alexander I, William H, Stimson. Cytotoxic diterpenes from Scoparia dulcis. Journal of natural Products 2003; 66(7): 95-961. 